\title{
Study on VSCF wind power generation system control based on DSP
}

\author{
TANG Ya-ping \\ (Hunan Railway Professional Technology College, ZhuZhou Hunan 412001)
}

Keywords: Doubly fed induction generator; PWM converter; system simulation; decoupling control

\begin{abstract}
According to the characteristics of double fed asynchronous generator rotor energy flow, research and design based on the DSP control with two-way flow of energy function of Dual PWM converter and discusses the grid side converter control method of Dual PWM converter in particular. The wind turbine simulation model is established by using the electromagnetic transient PSCAD/EMTDC software. The simulation system is used to simulate the P, Q decoupling control and maximum wind energy tracking control of the generator.
\end{abstract}

\section{Introduction}

Wind is a natural phenomenon generated by the solar radiation heat, the earth's surface caused by uneven heating of the atmosphere. It is estimated that only $1 \%$ of the wind on the ground will be able to meet the needs of the world's energy. With the continuous improvement of the level of wind power generation technology, the cost of wind power gradually reduced, considering environmental benefits, the cost will be close to the cost of coal-fired power generation. Therefore, great efforts to develop wind energy as the representative of the renewable energy and new energy, to achieve sustainable development, has become the consensus of the whole society, strategic choice to solve the energy crisis and environmental problems.

\section{Overview of control technology of doubly fed wind power generation}

Wind power is the kinetic energy contained in the natural wind into electrical energy in the process, the wind turbine wind energy capture and convert it into mechanical energy, driven by rotary generator, and the generator for converting mechanical energy conversion into electrical energy. As countries around the world pay more attention to wind power, wind power has become the world's fastest, most widely studied and applied new energy technology. With the development of wind power technology, wind turbine, wind turbine generator, converter and its control system and the way of the wind turbine, there are different types of. Among them, the doubly fed wind power generation system due to the converter control capacity is small, the speed of operation range wide characteristics become currently the world's most widely used VSCF wind power generation system.

Variable speed constant frequency generator in asynchronous generator rotor side applied three-phase low frequency current to realize AC excitation, the output power is constant frequency and constant voltage amplitude, frequency, phase of the exciting current control. At the same time, the active power and reactive power decoupling control of the generator is realized by using the vector control technology. Control active power capable of adjusting the rotation speed of the wind turbine, to capture the maximum wind power tracking control; regulation of reactive power adjustable power factor and improve the dynamic and static stability of the wind turbine and power system operation. In addition, the VSCF wind power generation technology, so to achieve good flexible connection between the generator and power grid system, compared with the traditional constant speed constant frequency generation system easier to achieve grid connected operation and operation

\section{Control strategy of grid side converter}

Dual PWM converter in the grid side converter and machine side converter main circuit 
structure is exactly the same, and their reciprocal: when changing the DFIG rotor side energy flows, can realize the function of the rectifier and the inverter interchangeably. However, due to the different functions in the whole excitation system, the specific control methods are also different. The machine side converter adopts DFIG stator flux oriented vector control, the grid side converter will use the grid voltage oriented vector control mode. Side Converter Grid (GSC), its main function is to maintain the DC link voltage is constant, and can be in a certain range of network side power factor control or voltage regulation. The converter is connected with the motor said for the rotor side converter (rotor side converter, the RSC), to realize as the main purpose, control output active power of generator which can adjust the speed and capture maximum wind energy for wind energy utilization is maximized power decoupling control active power and reactive of the output of the power system, reactive power control of DFIG stator power factor can be adjusted, wind power system reactive power control and voltage control function.

The control of grid side converter GSC mainly include the control of DC voltage and AC current control two aspects, in the control system of three-phase voltage source converter, the general use of the typical double loop structure: voltage outer loop control and current loop control. The main function of the voltage outer loop is to keep the converter DC voltage constant. The main function of the current inner loop is to control the active power of the converter and the power factor of the AC side of the converter.

Current regulation device output by feedforward compensation decoupling as PWM voltage, to produce the corresponding PWM waveform, to control the on-off of the converter bridge arm. References: synchronous coordinates by the $\mathrm{D}$ and $\mathrm{q}$ axis currents exist cross coupling and the shaft contains AC input voltage disturbance, these disturbance factors will increase control the complexity of the system design, reduce the control effects of the conventional control system. In order to eliminate the influence of the disturbance, in the D and $\mathrm{q}$ axis current controller using appropriate strategies make the $\mathrm{D}$ and $\mathrm{q}$ axis currents are decoupled from one another, and Realization of AC input voltage disturbance feedforward compensation ${ }^{[1,2]}$, so the following equation:

$$
\left\{\begin{array}{l}
v_{d}^{*}=-\left(k_{i p}+\frac{k_{i i}}{s}\right)\left(i_{d}^{*}-i_{d}\right)+\omega_{1} L i_{q}+u_{d} \\
v_{q}^{*}=-\left(k_{i p}+\frac{k_{i i}}{s}\right)\left(i_{q}^{*}-i_{q}\right)+\omega_{1} L i_{d}+u_{q}
\end{array}\right.
$$

$k_{i p}, k_{i i}-$ Coefficient and integral coefficient of current loop;

$v_{d}^{*}, v_{q}^{*} \_$AC side $\mathrm{d}, \mathrm{q}$ axis modulation voltage reference value;

$i_{d}^{*}, i_{q}^{*} \longrightarrow$ AC side d, q axis current setting value;

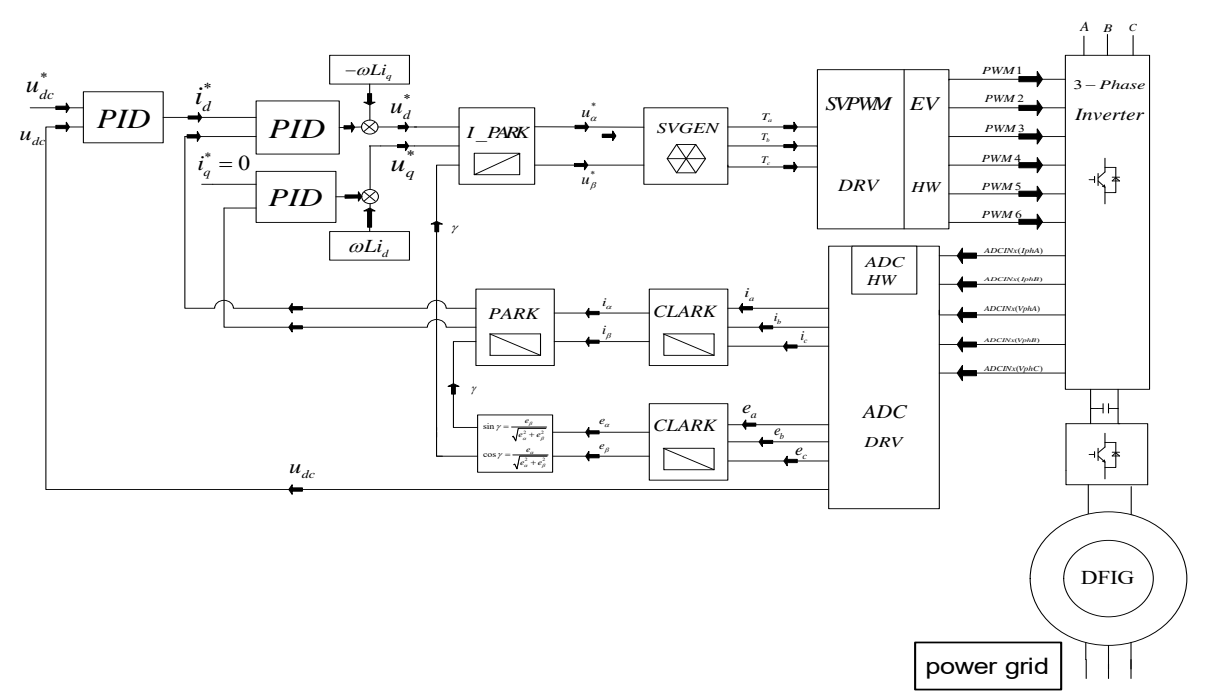

Fig. 1 double loop control block diagram of network side GSC converter 
Typical double loop control structure as shown in Figure 1. Among them, outer loop DC side capacitor voltage is maintained, the regulator output determines the magnitude and direction of the converter output power and as the inner active current given; inner current loop is on ring regulator output and the AC side power factor demand regulated PWM inverter AC input current.

\section{GSC net side converter}

The grid side converter for AC lateral line voltage, phase voltage waveform, waveform of active power and reactive power waveform, and a phase SVPWM waveform is shown in Fig.2.

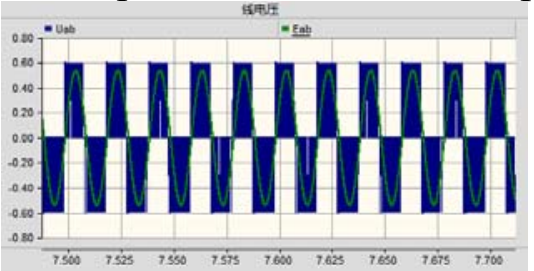

Fig.2 (a) AC side voltage waveform

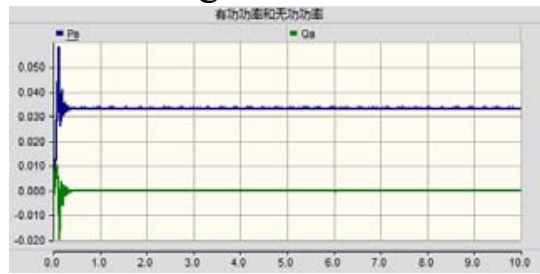

Fig.2 (c) Active power and reactive power waveform modulation waveform

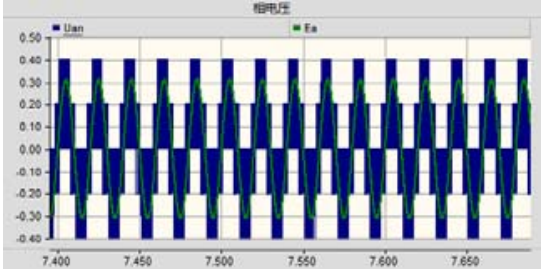

Fig. 2（b） voltage waveform of AC side

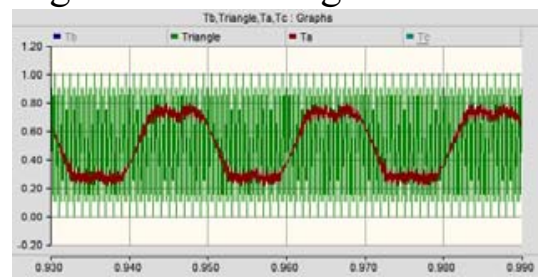

Fig.2 (d)Phase SVPWM

Fig. 3 and Fig. 4 represent, respectively, when the grid side converter working in the rectifier and the inverter DC link voltage and AC grid side voltage and current, visible grid side converter rectifier operation, the $\mathrm{AC}$ side current and voltage phase, energy is out of the grid; the grid side converter inverter mode operation, the AC side current and voltage in anti phase, the energy is flowing into grid. This shows that the dual PWM type converter has the ability of two-way flow of energy. As can be seen from the graph, the input and output characteristics of the dual PWM converter are good, and the harmonic is little. Whether the state of the rectifier or inverter, the DC link voltage is relatively stable.
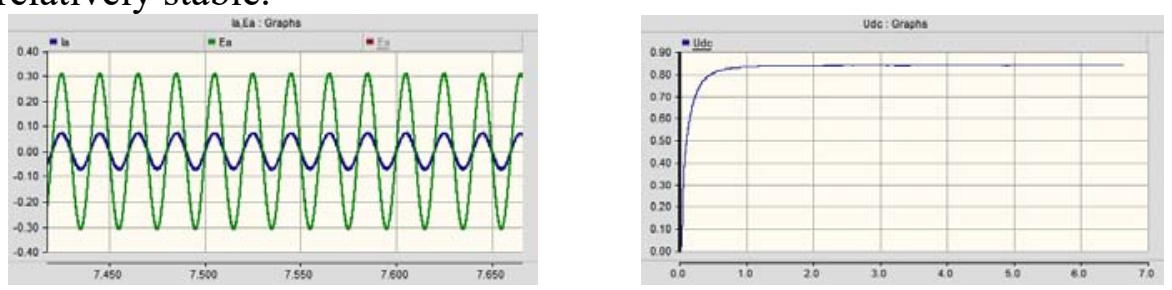

Fig. 3 the DC link voltage and the AC side power grid voltage and current in the rectifier state of the network side converter
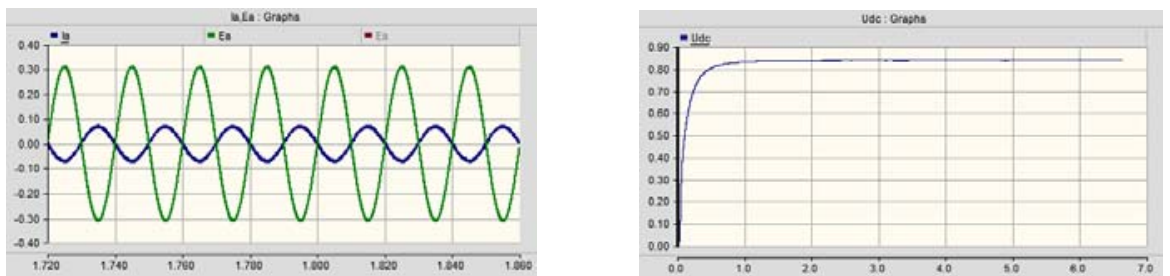

Fig. 4 the DC link voltage and the AC side power grid voltage and current in the inverter state of the network side converter

\section{Conclusion}

As a renewable green energy, wind energy has become more and more widespread attention all over the world, all in the policy on the development of wind power industry on the preferential, capital investment. China is also included in the recent wind power development goals, as the focus 
of the country's follow-up energy research and development. The under the tutor's subject group funded, with DSP of TI company advanced control chip as the core, AC excited VSCF wind power generation experiment platform is built, to acquire a knowledge of many laws, made some theory with practical innovation achievements.

Analysis of doubly fed induction generator (DFIG) operation theory, under discussion on the basis of the DFIG mathematical model and equivalent circuit, in-depth study of the operation characteristics and power relations, to control the power of generator and excitation with converter design laid a theoretical foundation.

\section{References:}

[1] Jiang Congdi. Discussion on the operation and control of VSCF wind power generation system [J]. Electronic technology and software engineering, 2015, (3):226-227.

[2] Zhang Lulu. The maximum wind power tracking control of VSCF wind power generation system is discussed [J]. China Hi tech enterprise, 2015, (34):119-120.

[3] Li Fuzhu. Wang Cuntang. Guo Yuqin. Nonlinear controller design model of VSCF wind power generation system [J]. Journal of solar energy, 2015:36 (10) 2429 - 2433.

[4] Rahul Dutta, Wang Feng, Bradley F, et al. Analysis ofshort-term energy storage for midsize hydrostatic wind turbine $[\mathrm{J}]$. Journal of Dynamic Systems, Measurement and Control, 2014, 136 (7): 1-10.

[5] Thomsen Knud Erik. Technological advances in hydraulic drivetrains for wind turbines [J] . Energy Procedia, 2012, 24 (1): 76-82.

[6] Wang Yan. Modeling and control for variable-pump controlling variable-motor [J]. Control Theory \&Applications, 2012, 29 (1): 41-47.. 